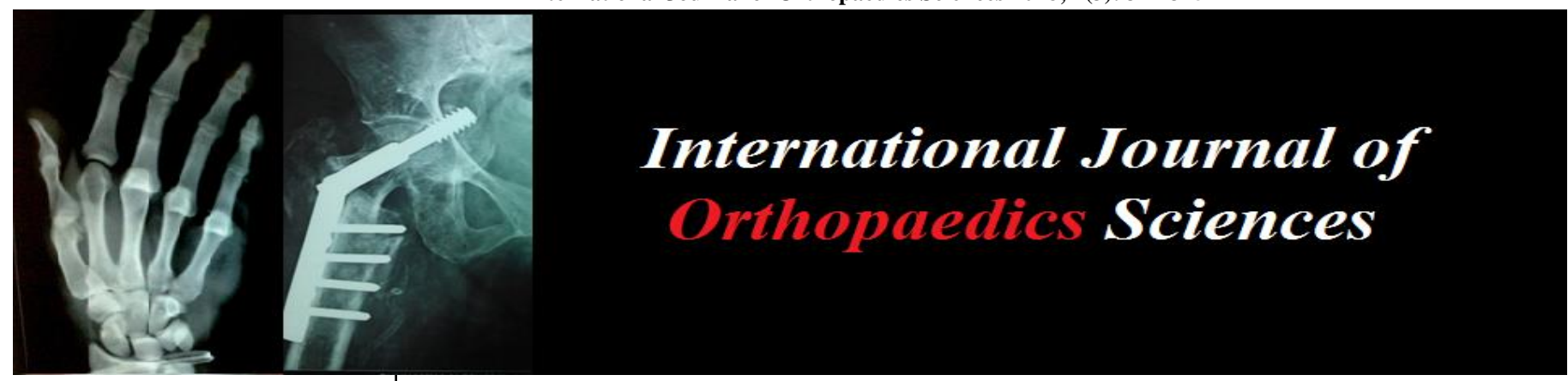

ISSN: $2395-1958$

IJOS 2018; 4(3): 322-325

(C) 2018 IJOS

www.orthopaper.com

Received: 28-05-2018

Accepted: 29-06-2018

Dr. Yogesh C Patel

Professor, Orthopaedics, S.S.G

Hospital, Vadodara, Gujarat,

India

Dr. Pinkal H Thakkar

Senior Resident, Orthopaedics,

S.S.G. Hospital, Vadodara,

Gujarat, India

Dr. Alizygam Hasan

Senior Resident, Orthopaedics,

S.S.G. Hospital, Vadodara,

Gujarat, India

Dr. Bhavik K Ahir

Junior Resident, Orthopaedics, S.S.G. Hospital, Vadodara,

Gujarat, India
Correspondence

Dr. Pinkal H Thakkar

Senior Resident, Orthopaedics,

S.S.G. Hospital, Vadodara,

Gujarat, India

\section{Study of lower end radius fractures treated with external fixator with or without $K$ wire}

\author{
Dr. Yogesh C Patel, Dr. Pinkal H Thakkar, Dr. Alizygam Hasan and \\ Dr. Bhavik K Ahir
}

DOI: https://doi.org/10.22271/ortho.2018.v4.i3f.58

\section{Abstract}

Objectives: A prospective study of management of fracture distal radius by external fixator using the principle of ligamentotaxis was conducted from July 2016 to August 2017 at our institute to evaluate the clinical efficacy of external fixator with ligamentotaxis in distal radius fracture reduction, fracture healing, functional recovery after surgery.

Material and Methods: 30 cases of fracture distal radius were treated with ligamentotaxis. Inclusion criterias were 1) skeletally mature patients having age more than 18 years 2) closed/unstable fractures. 3 ) Frykman type 1 to 8 fractures. 4) Fractures with history of trauma <2 weeks. 5) Patients with 6 months follow up. 6) Medically fit patients. Fracture was anantomically reduced and fixed with external fixator with principle of ligamentotaxis. Patients were evaluated based on Modified Demerit point system of Gartland and Werley.

Results: With external fixation and ligamentotaxis, the result in majority of cases was excellent to good. Hence this study conclude that external fixator with ligamentotaxis is a good method of treatment in fracture lower end of radius.

Keywords: Distal radius, external fixator, fracture, ligamentotaxis

\section{Introduction}

Distal radius fractures represent approximately one-sixth of all fractures treated in emergency departments. There seems to be a growing incidence of these fractures in all age groups with the sharpest increase seen in both elderly females and younger adult males ${ }^{[1,2,3]}$. Current data suggest that distal radius fractures in the elderly may represent an insufficiency fracture associated with all of the risk factors for osteoporosis ${ }^{[4]}$. In 1814, Abraham Colles, Prof of anatomy and surgery of Trinity college of Dublin clearly defined the fracture and outlined the treatment modality, and devised plaster of paris cast still commonly used called "Colle"s cast". He stated that "fracture takes place about an inch and half above the extremity of radius. In 1977, external fixator method gained popularity among orthopaedicians with Vidal Jacques described original method of treatment of these fractures with ligamentotaxis ${ }^{[5]}$. Since their description by Colles in 1814 , distal radial fractures remain a therapeutic challenge ${ }^{[6]}$. A prospective study of management of fracture distal radius by external fixator using the principle of ligamentotaxis was conducted to evaluate for the clinical efficacy of external fixator with ligamentotaxis in distal radius fracture reduction, fracture healing, functional recovery after surgery.

\section{Material and Methods}

A total number of 30 cases of lower end radius fracture treated by ligamentotaxis were studied from July 2016 to August 2017 admitted in S.S.G. Hospital, Vadodara, Gujarat, India. AO type External Fixation with 2 shantz pin in radius \& 2 shantz pins in metacarpal were applied. Inclusion criteria were 1) skeletally mature patients having age more than 18 years 2) closed/unstable fractures. 3) Frykman type 1 to 8 fractures. 4) Fractures with history of trauma $<2$ weeks. 5) Patients with 6 months follow up. 6) Medically fit patients. Exclusion Criteria were 1) Fractures in age <18 years 2) Pregnant females 3) Pathological fractures 4) Old neglected fractures (>4 weeks old) 5) All open grade 3 fractures 6) Crush Injury 7) RadioCarpal fracture dislocation. 
All fractures were classified according to Frykman's classification (Type I to VIII). Baseline demographic and injury characteristics were recorded. In this study of 30 patients, $11(36 \%)$ cases were frykman's type III, 5(16.6\%) had type VII, 4(13.3\%) had type IV \& type I, 3(10\%) were type type II, V \& VIII fractures. All 30 patients were followed upto 6 months final follow up. 16(53.33\%) were male and $14(46.67 \%)$ were females. The dominant wrist was involved in $20(66.66 \%)$ cases \& $10(33.34 \%)$ cases had their nondominant wrist involved. The patients in young working age group 20-40yrs were 10 cases representing $33.33 \%$ of our cases. The number of cases in complex intra-articular fractures i.e. Frykman's type VII and VIII represented $8(26.6 \%)$ of our cases. Number of cases due to fall on outstretched hand were $13(43.43 \%)$ of our cases \& $13(43.35 \%)$ of cases were due to road traffic accident. $7(23 \%)$ of cases had associated injuries.

These results of all patients were evaluated as per the criteria suggested by Gartland and Werley (Functional) ${ }^{[7]}$ [Table $1 \&$ 2].

Table 1: Modified Demerit Point System of Gartland and Werley.

\begin{tabular}{|c|c|}
\hline Category & Points \\
\hline \multicolumn{2}{|l|}{ Residual deformity (0-3 Points) } \\
\hline Prominent ulnar styloid process & 1 \\
\hline Residual dorsal tilt. & 2 \\
\hline Residual deviation of hand & $2-3$ \\
\hline \multicolumn{2}{|l|}{ Subjective evaluation (0-6 points) } \\
\hline Excellent: No pain, disability or limitation of motion & 0 \\
\hline Good: Occasional pain, some limitation of motion and no disability & 2 \\
\hline Fair: Occasional pain, some limitation of motion, weakness in wrist, activities slightly restricted. & 4 \\
\hline Poor: Pain limitation of motion, disability, Activities more or less markedly restricted. & 6 \\
\hline \multicolumn{2}{|l|}{ Objective evaluation (0-5 points) } \\
\hline Loss of dorsiflexion & 5 \\
\hline Loss of ulnardeviation & 3 \\
\hline Loss of supination & 2 \\
\hline Loss of Palmarflexion & 1 \\
\hline Loss of radial deviation & 1 \\
\hline Loss of circumduction & 1 \\
\hline Pain in distal radioulnar joint & 1 \\
\hline Grip strength $60 \%$ or less than opposite side & 1 \\
\hline Loss of pronation & 2 \\
\hline \multicolumn{2}{|l|}{ Arthritic changes } \\
\hline Minimum & 1 \\
\hline Minimum with pain & 3 \\
\hline Moderate & 2 \\
\hline Moderate with pain & 4 \\
\hline Severe & 3 \\
\hline Severe with pain & 5 \\
\hline Nerve complications (Median) & $1-3$ \\
\hline Poor finger functions due to cast & $1-2$ \\
\hline
\end{tabular}

Table 2: Grading

\begin{tabular}{|c|c|}
\hline Excellent & $0-2$ \\
\hline Good & $3-8$ \\
\hline Fair & $9-20$ \\
\hline Poor & $>21$ \\
\hline
\end{tabular}

\subsection{Operative procedure}

Majority of surgeries were performed within 24 to 48 hours of admission. In all cases, the fixator was applied before fracture manipulation in a trans-articular fashion. Once reduction was achieved, Additional K-wire was used when required for stabilization. On achieving the desired reduction the wrist was locked and plced in a functional position. Finally, under the image intensifier, the minimum required distraction was applied across the wrist. Distal radioulnar joint instability was assessed and corrected by reducing and transfixing with $\mathrm{K}$ wires from distal ulna to distal radius when required. Most of the cases were treated with external fixator on the day of injury within 8 hrs of injury. The fixator was removed after 6 wks followed by hot paraffin wax bath treatment and active physiotherapy. The follow up period averaged 4 months the highest being 6 months and the least being 3 months.

\subsection{Results}

This study achieved excellent results in 13(43\%) patients, good in $11(37 \%)$ patients, fair in $5(17 \%)$ patients, poor in $1(3 \%)$ patients evaluated as per the criteria suggested by Gartland and Werley (Functional). (Case 1\&2) In this study, $7(20 \%)$ had wrist pain and stiffness and $1(3.33 \%)$ had poor finger function due to malunion. Out of those 7 patients 5 had prominent ulnar styloid secondary to malunion or DRUJ instability. Wrist pain and stiffness and finger stiffness significantly improved after physiotherapy. 2 patients $(6.66 \%)$ had pin tract infection \& loosening. 

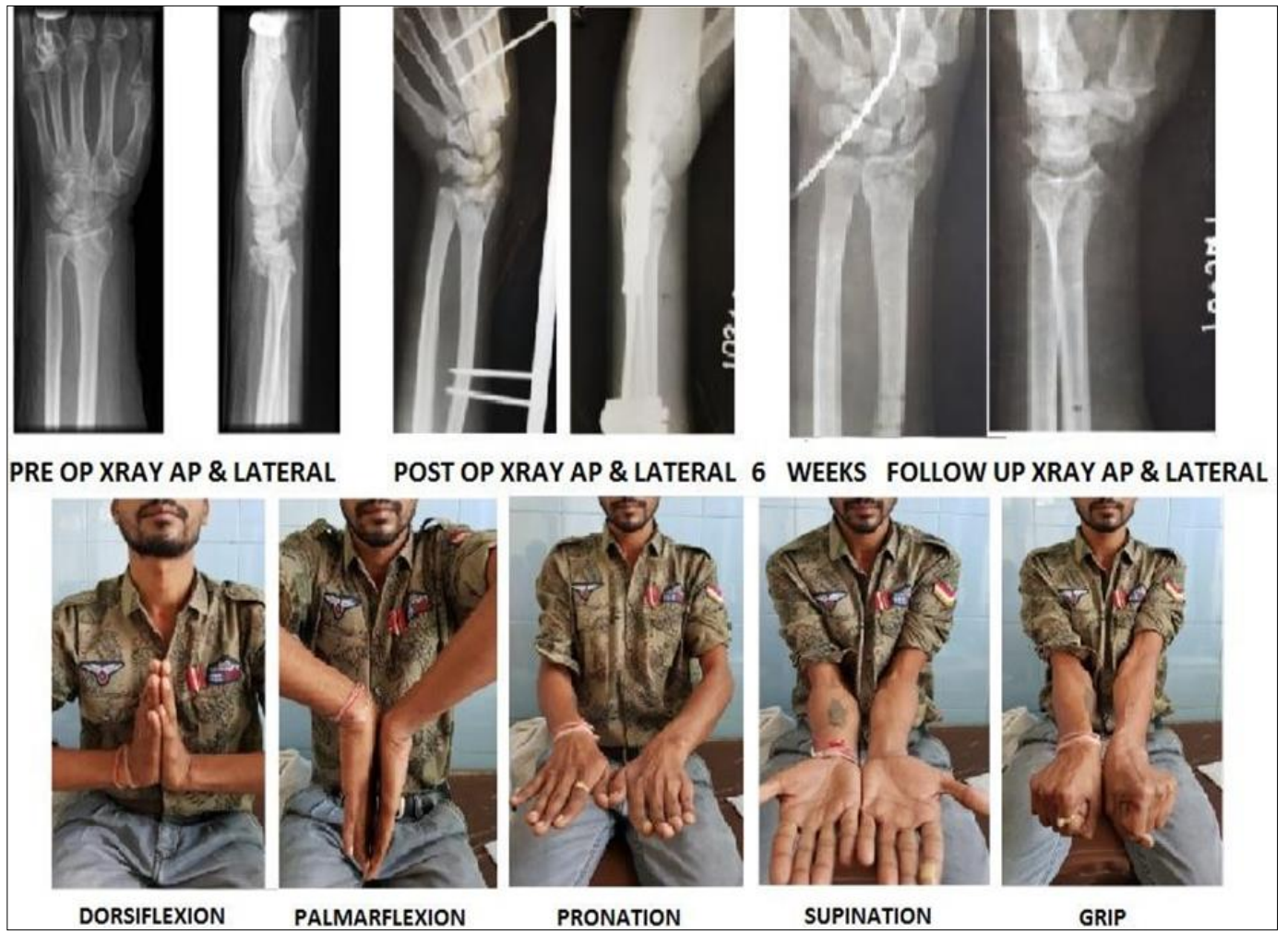

Case 1
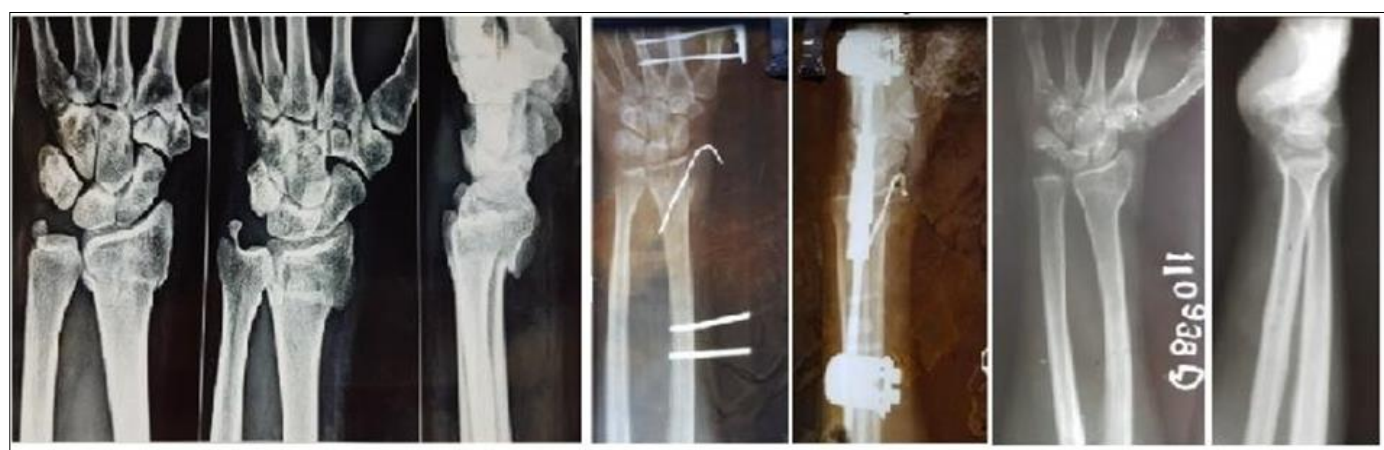

PRE OP AP \& LATERAL XRAY

POST OP XRAY AP \& LATERAL

6 WEEKS FOLLOW UP

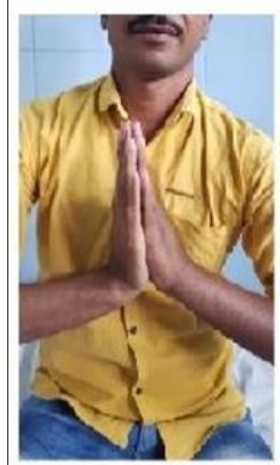

DORSIFLEXION

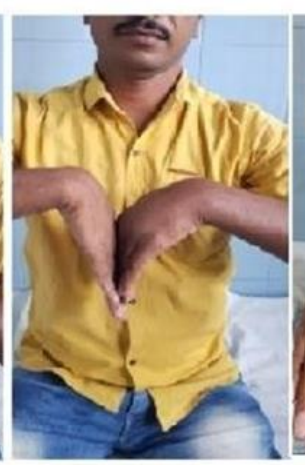

PALMAR FLEXION
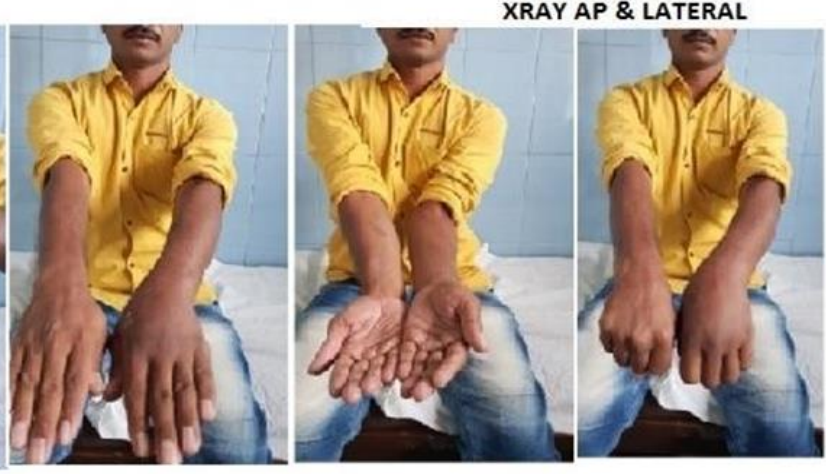

PRONATION

SUPINATION

GRIP

Case 2

Our case series attributes to $80 \%$ of excellent to good results and $20 \%$ of fair to poor results. Thus, it suggests that ligamentotaxis plays a good role in anatomic restoration in unstable fractures as well as intra articular fractures.

\section{Discussion}

The fracture of distal end radius is the most common fracture we treat in emergency department. Management of fracture distal end of radius is still a challenge for orthopaedic surgeon and pose therapeutic problem in term of reduction of fracture, maintenance of reduction till the fracture unites, mobility of the joint after fracture union. Failure in the management may cause permanent disability ${ }^{[8]}$. But the outcome of these fractures is not uniformly good regardless of treatment instituted. We agree with green that a good functional result usually accompanies a good anatomical reduction ${ }^{[9]}$. The small A.O external fixator provides a simple and reliable means of treating distal end radial fractures especially unstable intraarticular fractures employing the concept of ligamentotaxis that was proposed by Vidal et al. ${ }^{[10]}$ The 
efficacy of ligamentotaxis in neutralizing detrimental compression forces, which are likely to cause displacement of unstable fracture with radial shortening, is a significant and increasingly appealing advance in the management of distal radius fracture ${ }^{[11]}$.

Biomechanical studies by Nakata et al. showed the resistance of A.O devices to axial loading to be greater than that of most other fixators ${ }^{[12]}$.

In 1961, Dowling and Sawyer evaluated results of percutaneus pinning fixation in 51 patients with $84 \%$ excellent to good results ${ }^{[13]}$. In 1979, Cooney et al. published results of 60 patients treated with R.A Frame with $87 \%$ excellent to good results ${ }^{[14]}$. In 1984, D'Anca et al. evaluated results of Hoffman fixation in 54 patients with 94\% excellent to good results ${ }^{[15]}$. In 1989, Howard evaluated results of Hoffman fixation in 50 patients with $96 \%$ excellent to good results. In April 2001, Markowitz AD published a paper on five pin external fixator and early mobilization. They emphasized to use on dorsal pin (additional) incorporated in external fixator to correct dorsal tilt found in many fractures of distal end radius. Additional pins would help to reduce those fragments that would not improve with traction alone, thus unnecessary excessive traction is avoided [16]. In 2010, Aktekin et al. found that wrist extension, ulnar deviation, palmar tilt and radial height were better in those treated with external fixation ${ }^{[17]}$. In 2013, Rajeev shukla et al. concluded from their studies in 72 cases of intraarticular distal radius fractures that Joshiees External Stabilizing System is a cost effective technique and a good option in displaced distal end radial fractures ${ }^{[18]}$. Our case series attributes to $80 \%$ of excellent to good results and $20 \%$ of fair to poor results. [Table-3].

Table 3: Functional Results of Various Case Series

\begin{tabular}{|c|c|c|c|c|c|}
\hline \multirow{2}{*}{ S. No } & \multirow{2}{*}{ Name of Series } & \multirow{2}{*}{ Modality of treatment } & \multirow{2}{*}{ Number of cases } & \multicolumn{2}{|c|}{ Results (Functional) } \\
\hline & & & & $\mathbf{E} / \mathbf{G}$ & $\mathbf{F} / \mathbf{P}$ \\
\hline 1. & Dowling and sawyer (1961) ${ }^{[13]}$ & Percutaneous Pinning & 51 & $84 \%$ & $16 \%$ \\
\hline 2. & Cooney et al. (1979) $)^{[14]}$ & R.A Frame & 60 & $87 \%$ & $13 \%$ \\
\hline 3. & $\mathrm{D}^{\text {ceAnca } \text { et al. }(1984)^{[15]}}$ & Hoffmann & 54 & $94 \%$ & $06 \%$ \\
\hline 4. & Howard 1989 & Hoffmann & 50 & $96 \%$ & $4 \%$ \\
\hline 5. & Rajeev Shukla (2013) $^{[18]}$ & JESS & 72 & $77.8 \%$ & $22.2 \%$ \\
\hline 6. & Our series (Present study) & A.O & 30 & $80 \%$ & $20 \%$ \\
\hline
\end{tabular}

\section{Conclusion}

The following conclusions can be made from our series. 1) The distinct advantage of external fixator are its superior mechanical efficiency, its capacity for fracture adjustment during healing period. 2) The small A.O external fixator is a simple device and easy and safe to use even under regional anesthesia. 3) The shorter period of surgery, minimal exposure, no need for tourniquet are its distinct advantage over plate fixation.4) Can be performed in emergency with minimum instrumentation and expertise i.e. even by a trainee. 5) The use of external fixator is an effective method of treating unstable extraarticular and complex intraarticular fractures of the distal end radius.

Finally we would like to conclude that External fixator is an easy, cost effective, reliable and most suitable treatment in treating intraarticular and unstable extraarticular distal end radial fractures by the Principle of ligamentotaxis".

\section{References}

1. Swiontkowski MF. Increasing rates of forearm fractures in children. JAMA. 2003; 290(24):3193.

2. Solgaard S, Petersen VS. Epidemiology of distal radius fractures. Acta Orthop Scand. 1985; 56(5):391-393.

3. Mensforth RP, Latimer BM. Hamann-Todd Collection aging studies: osteoporosis fracture syndrome. Am J Phys Anthropology. 1989; 80(4):461-479.

4. Nguyen TV, Center JR, Sambrook PN. Risk factors for proximal humerus, forearm, and wrist fractures in elderly men and women: the Dubbo Osteoporosis Epidemiology Study. Am J Epidemiology. 2001; 153(6):587-595.

5. Vidal, Fischbach, Brahin Act Orthop Belgium. 1977; 43:781-789.

6. Colles A. On the fracture of the carpal extremity of the radius. Edinb Med Surg J. 1814, 10:181.

7. Gartland J, Werley C. Evaluation of healed Colles' fractures. J Bone Joint Surg. 1951; 33(4):895-907.

8. Boparai RPS, Boparai RS, Kapilar, Pandher DS. Role of ligamentotaxis in management of comminuted intra/juxta articular fractures. IJO. 2006; 40(3):185-7.

9. Green DP. Pins and plaster treatment of comminuted fracture of the distal end of the radius. JBJS, 1975; 57A:304-310.

10. Vidal Buscayret J, Fischbach. Une methode originale dans le traitement des fractures comminutives de du radius Le taxis ligamentaire Acta Orthop. Belgica. 1977; 43:781-789.

11. Robert Bocholz W, James Hackman D. Rockwood and Greens fracture in adults 5th edition. 1:829-880.

12. Nakata RY, Chand Yogesh Matika. External fixation for wrist fractures: a biomechanical and clinical study Jr. Hand Surgery. 1986; 10(A):845-851.

13. Dowling JJ, Sawyer Blackwell. Comminuted Colles fractures evaluation of method of treatment JBJS. 1961; 43-A:657-668.

14. Cooney WP, Agee JM, Hastings HI, Melone CPJ, Rayhack JM. Management of Intraarticular Fractures of the Distal Radius. Contemp Ortho. 1990; 21:71-104.

15. D Anca AF, Byron TW, Feinstein PA. External fixator management of unstable Colles fractures Orthopedics. 1984; 7:853-9.

16. Markiewitz AD. Five pin external fixator and early range of motion for distal radius fracture, Orth, Clinics of North America, 2000.

17. Aktekin CN, Altay M, Gursoy C. Comparison between external fixation and cast treatment in the management of distal radius fractures in patients aged 65 years and older, J Hand Surg. 2010; 35:86.

18. Rajeev Shukla. A multifactorial study of application of Joshiees External Stabilizing System in displaced Distal End Radius Fractures. Indian Journal of Basic and Applied M. 